\title{
Establishment of long-term monolayer cultures of somatic cells from human fetal testes and expansion of peritubular myoid cells in the presence of androgen
}

\author{
Gillian Cowan, Andrew J Childs, Richard A Anderson ${ }^{1}$ and Philippa T K Saunders \\ MRC Human Reproductive Sciences Unit, Queen's Medical Research Institute, 47 Little France Crescent, Edinburgh \\ EH16 4TJ, UK and ${ }^{1}$ Division of Development and Reproductive Sciences, Queen's Medical Research Institute, \\ University of Edinburgh, 47 Little France Crescent, Edinburgh EH16 4TJ, UK
}

Correspondence should be addressed to P T K Saunders; Email: p.saunders@ed.ac.uk

\begin{abstract}
The somatic (Sertoli cell (SC), Leydig cell (LC), and peritubular myoid (PTM) cell) cells play key roles in development of the fetal testis. We established monolayer cultures from second trimester human testes and investigated the pattern of expression of cell-lineage characteristic mRNAs. Expression of some SC-associated genes (SRY, SOX9, WT1, GATA4, and SF1) was detectable up to and including passage 3 (P3), while others (anti-Müllerian hormone; desert hedgehog) present prior to dissociation were not expressed in the cultured cells. Transcripts encoding the androgen receptor were expressed but addition of dihydrotestosterone (DHT) had no impact on expression of mRNAs expressed in SC or LC. Total concentrations of mRNAs encoding smooth muscle actin (ACTA2) and desmin increased from P1 to P3; an increasing proportion of the cells in the cultures were immunopositive for ACTA2 consistent with proliferation/differentiation of PTM cells. In conclusion, somatic cell monolayer cultures were established from human fetal testes; these cultures could form the basis for future studies based on isolation of purified populations of somatic cells and manipulation of gene expression that is difficult to achieve with organ culture systems. Our results suggest that fetal SC do not maintain a fully differentiated phenotype in vitro, yet PTM (ACTA2 positive) cells readily adapt to monolayer culture conditions in the presence of DHT. This culture system provides an opportunity to study the impact of regulatory factors on gene expression in PTM cells, a population thought to play a key role in mediating androgen action within the developing testis.
\end{abstract}

Reproduction (2010) 139 749-757

\section{Introduction}

Normal maturation of the germ cell population and establishment of the male phenotype is regulated by factors produced by the somatic cell populations in the fetal testis including Sertoli cell (SC), Leydig cell (LC), and peritubular myoid (PTM) cell types. In the human fetal gonad, testis cords consisting of SC and fetal germ cells (gonocytes) form between the 7th and 9th weeks of gestation. In the second trimester, the cords are surrounded by a layer of PTM cells and a substantial interstitial compartment containing steroidogenically active LC and blood vessels (Gaskell et al. 2004). Specification and differentiation of the SC lineage are central to male gonadal development and begins when cells within the genital ridge differentiate into SC precursors in response to the expression of a protein encoded by the sex-determining region on the $\mathrm{Y}$ chromosome (SRY) gene (Hacker et al. 1995, Bullejos \& Koopman 2001) expression of which is associated with upregulation of male-specific genes including the SRY-like HMG-box protein SOX9 (Bishop et al. 2000,
Vidal et al. 2001). The fetal SC also synthesise antiMüllerian hormone $(\mathrm{AMH})$ : a secreted glycoprotein that plays a critical role in remodeling of the reproductive tract in males (Hacker et al. 1995, De Santa Barbara et al. 1998, Rajpert-De Meyts et al. 1999). The expression of $\mathrm{AMH}$ is in turn regulated by transcription factors including the orphan nuclear receptor, steroidogenic factor 1 (SF1; Sekido \& Lovell-Badge 2008), a member of the GATA family of zinc finger proteins, GATA4 (Manuylov et al. 2007), and the product of the Wilms' tumor suppressor gene (WT1; Gao et al. 2006) all of which are expressed in SC in vivo.

Functional LC characterised by the expression of enzymes required for biosynthesis of testosterone including side-chain cleavage p450 (CYP11A1/SCCp450) and 3 - $\beta$-hydroxysteroid dehydrogenase (HSD3B/3 $\beta \mathrm{HSD}$; Murray et al. 2000) are evident from 9 weeks gestation in the human (Gaskell et al. 2004, Ostrer et al. 2007). The interstitial compartment also contains many cells thought to be undifferentiated fibroblasts as well as cells of the vasculature including endothelial cells 
(Brennan \& Capel 2004, Cool et al. 2008). The PTM cells surrounding the testis cords express myofibroblast proteins including $\alpha$-smooth muscle actin (ACTA2) and desmin (DES; Nishino et al. 2001). PTM cells were originally thought to migrate into the testis from the mesonephros but recent evidence suggests that differentiate from interstitial precursors within the gonad (Cool et al. 2008). With endothelial cells identified as the migrating cell population important for formation of testis cords, the precise role played by PTM in fetal life requires re-evaluation (Combes et al. 2009). We have previously demonstrated that expression of the androgen receptor $(A R)$ in the human fetal testis is confined to interstitial cell populations and is readily detectable in both fibroblasts cells and PTM cells (Majdic et al. 1995, Gaskell et al. 2004). Androgens are reported to promote differentiation of mesenchymal progenitors into cells committed to a myogenic lineage (Singh et al. 2003), and therefore, local biosynthesis of androgens within the fetal testis could play a critical role in differentiation of the PTM lineage.

Previous reports have described studies using organ cultures of human fetal testis recovered during the first (Lambrot et al. 2009) and second trimester (Robinson et al. 2003, Coutts et al. 2007, Hallmark et al. 2007) to investigate the impact of various agents including retinoic acid and environmental toxicants (Lambrot et al. 2006a, Coutts et al. 2007). Others have reported the use of short-term cultures (up to 6 days) of cells obtained following enzymatic digestion of testes obtained from infants and children to study the impact of hormones such as $\mathrm{LH}$ and FSH on gene expression (Berensztein et al. 1992, 2000, Rivarola et al. 1995). Cultures of SC established from 10-day-old mice expressing the large $\mathrm{T}$ antigen are reported to maintain a differentiated phenotype (Walther et al. 1996) and to respond to steroids (Sneddon et al. 2005), and however, to date, there have been no reports of long-term cultures of somatic cells established from human fetal testes. We therefore undertook a study using primary cells dissociated from second trimester fetal testes in order to examine the phenotype of cells in long-term monolayer cultures with the hope that we could propagate sufficient numbers of cells to allow us to isolate pure populations of somatic cells for studies of their developmental regulation.

\section{Results}

\section{Immunohistological analysis of second trimester testes and validation of cell-specific markers}

On tissue sections from human fetal testes recovered during the second trimester (14 and 20 weeks gestation), SC nuclei were immunopositive for SOX9 and SC cytoplasm was immunopositive for AMH (Fig. 1A and $B$ respectively). Presumptive LCs within the interstitium were immunopositive for HSD3B (Fig. 1C) and CYP11A1 (not shown). Immunoexpression of AR (Fig. 1D), ACTA2 (Fig. 1E), and DES (Fig. 1F) was confined to the
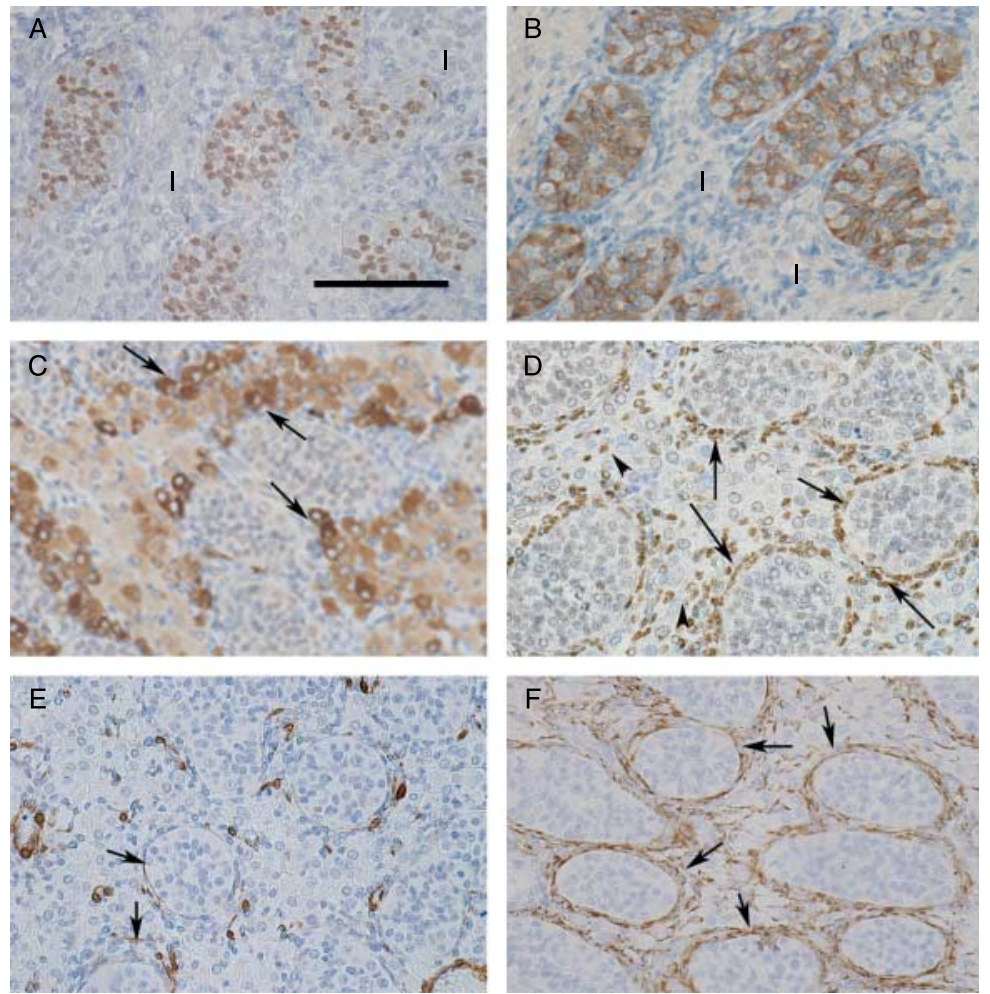

Figure 1 Immunohistochemical analysis of fixed tissue sections of testes obtained during the second trimester was used to confirm expression of somatic cell marker proteins. Sertoli cells: SOX9 (A), AMH (B). Leydig cells: HSD3B (3ßHSD) (C). Interstitial cell populations were immunopositive for AR (D) smooth muscle actin (ACTA2, E) and desmin (DES, F). Note that expression of ACTA2 was restricted to PTM surrounding the testis cords and vasculature; no immunopositive staining for AR was detected in the cords. Gestational ages: A, E 15 weeks; C, D 16 weeks; B, F, 17 weeks. All magnifications $\times 20$, scale bar $=100 \mu \mathrm{m}, I=$ interstitium, arrows point to PTM cells. 
interstititum. All three proteins were expressed in the PTM population, but expression of AR and DES was also apparent in populations of interstitial fibroblasts.

\section{Cellular morphology of cells derived from human testes in monolayer cultures}

Following enzymatic dispersal and establishment of monolayers, a mixture of cell morphologies was observed including small closely adherent cells, to round semi-adherent cells and cells which appeared long and flat (Fig. 2, passage 0, P0). At P0, cultures usually reached confluency within 4-6 days; although the time taken to reach confluency decreased with increasing passage number.

\section{Expression of somatic cell proteins in primary human testicular monolayers}

In order to determine whether the mixed cellular morphology detected in the cultures reflected the presence of different subtypes of somatic cells, cultures were immunostained with the same antibodies that were used for selective labeling of somatic cell types on fixed tissue sections. Presumptive SCs with SOX9 immunopositive nuclei were detected in all cultures regardless of passage number, although the number of positive cells appeared to decrease by P3 (Fig. 2). Immunoexpression of $\mathrm{AMH}$ was only detected in a few cells in a single culture at P0 (not shown), and all other cell cultures were immunonegative. Cells immunopositive for CYP11A1 were readily identified in all $\mathrm{PO}$ primary cultures, but were rare at $\mathrm{P} 1$ and never detected in cultures at $\mathrm{P} 2$ or $\mathrm{P} 3$ (Fig. 2). In contrast, immunoexpression of ACTA2 was detectable in a subpopulation of cells with extensive cytoplasm, regardless of passage number (Fig. 2, P0-P3 and not shown P4, P5).

\section{Evaluation of changes in total expression of somatic cell mRNAs}

In all experiments, the amount(s) of individual mRNAs in a fragment of testicular tissue recovered prior to enzymatic dispersal (designated as $t=0$ ) served as a reference for the relative expressions of cell type-specific mRNAs in individual cultures. In addition, a positive control sample prepared from mRNAs pooled from several second trimester testes was included in all experiments to allow for intra-assay variation (with the average amount of each mRNA in this pool set as 1 for the purposes of comparison). Although mRNAs known to be expressed in germ cell subtypes including gonocytes (POU5F1/OCT4) and pre-spermatogonia (DDX4/VASA; Gaskell et al. 2004) were readily detectable in the $t=0$ (pre-dissociated) samples, they were low/undetectable in P0 samples consistent with the expectation that germ
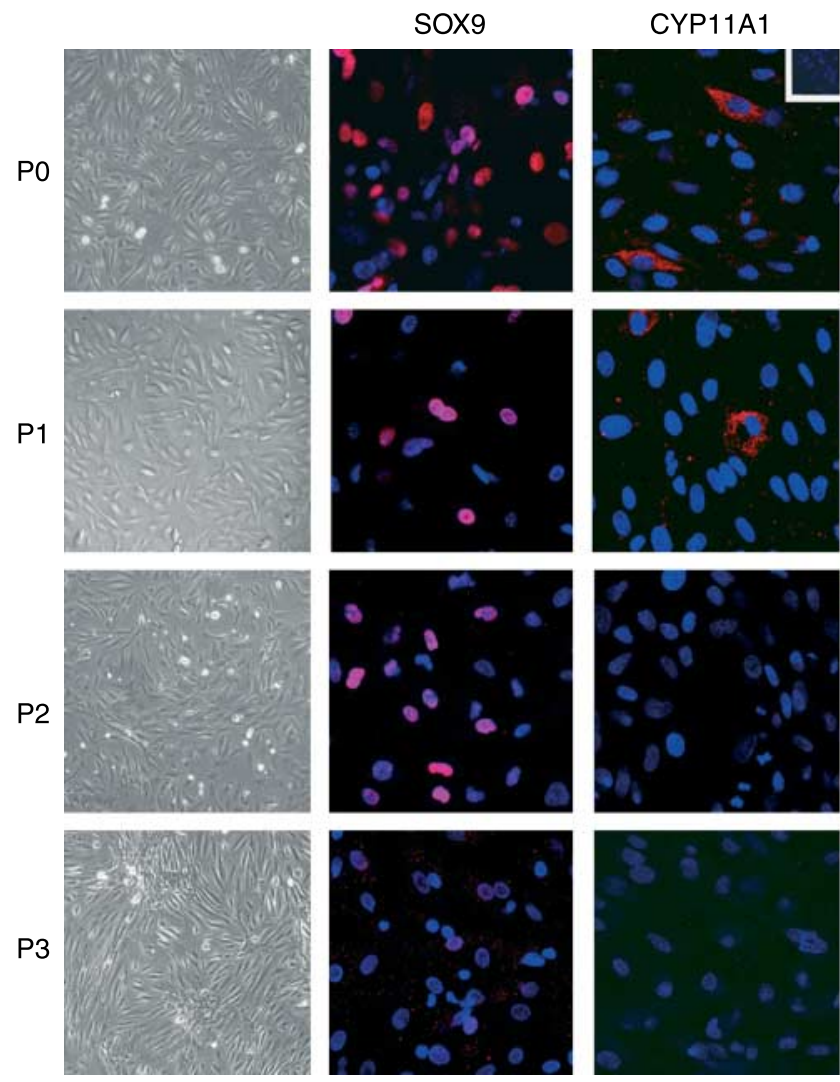

Figure 2 Gross morphology and protein expression in cultures established from cells dissociated from a 15-week human fetal testis shown at P0, P1, P2 and P3. Left hand panels: phase contrast. Immunofluorescent staining was obtained using antibodies directed against SOX9, CYP11A1 (SCCp450), and ACTA2. Inset shows negative control. Note expression of SOX9 (SC marker) was detected in cell nuclei in all cultures, whereas expression of the LC marker CYP11A1 was not present after P1. ACTA2 was detected in the cytoplasm of some cells in all cultures. 
cells would not adhere to the coated plastic of the flasks and would not therefore contribute to the monolayer cultures (data not shown).

Comparison of expression of the SC-specific mRNAs SOX9 and $A M H$ gave different results. Whereas expression of SOX9 mRNA was readily detectable in the cultured monolayers up to and including P3, $A M H$ mRNA was low/absent in extracts obtained from cells following enzymatic dispersal (Fig. 3, P0). Expression of CYP11A1 mRNA was readily detectable in P0 and P1 cultures but declined thereafter with significantly reduced expression at P3 compared with $t=0$ $(P<0.05)$ a finding consistent with immunostaining experiments suggesting that putative LC did not thrive following repeated enzymatic dispersal (Fig. 3). $A R$ mRNA was detected in total RNA recovered from monolayers up to and including P3 (Fig. 3), suggesting that a population of steroid-responsive interstitial cells was present in the cultures; based on immunostaining of cultures with anti-ACTA2 (Fig. 2), we would expect some of these to be PTM.

\section{Impact of androgen on expression of $m R N A s$ in somatic cell cultures}

During the second trimester, cells within the human fetal testis are exposed to high concentrations of androgen. We therefore tested whether addition of dihydrotestosterone (a nonaromatisable androgen that binds AR with high affinity (Askew et al. 2007)) altered expression of mRNAs in the monolayer cultures. The pattern of expression of the SC-specific mRNAs SOX9 and AMH
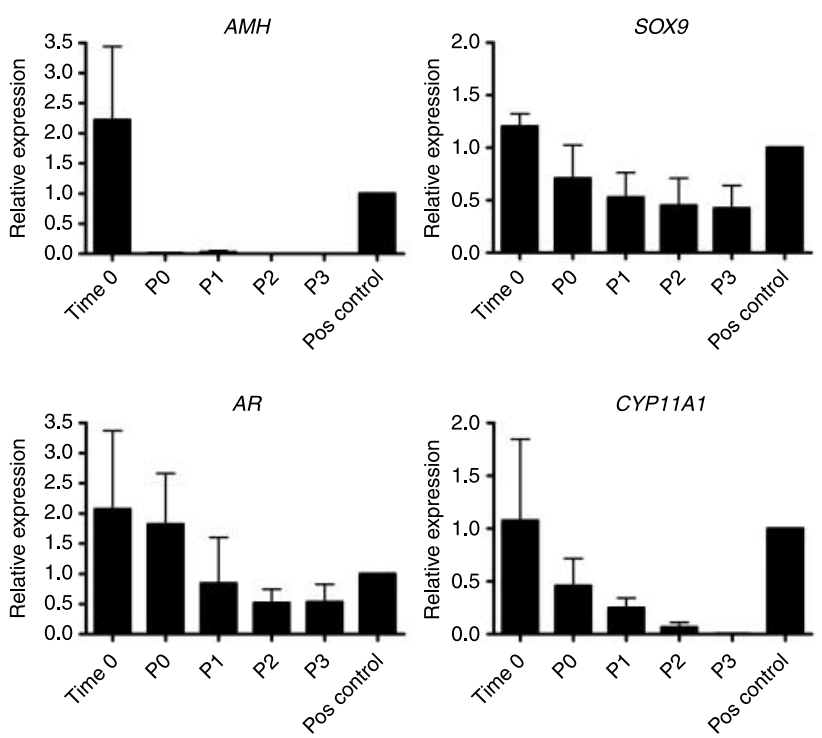

Figure 3 Expression of mRNAs in somatic cell monolayers. Expression of SOX9, AMH, AR, and CYP11A1 mRNAs determined by qRT-PCR using RNA extracted at time 0 (tissue recovery) and monolayer cultures at P0 to P3. Analysis was performed on three separate cultures, and data are shown relative to the positive control (pooled testis sample).

Mean \pm s.E.M.
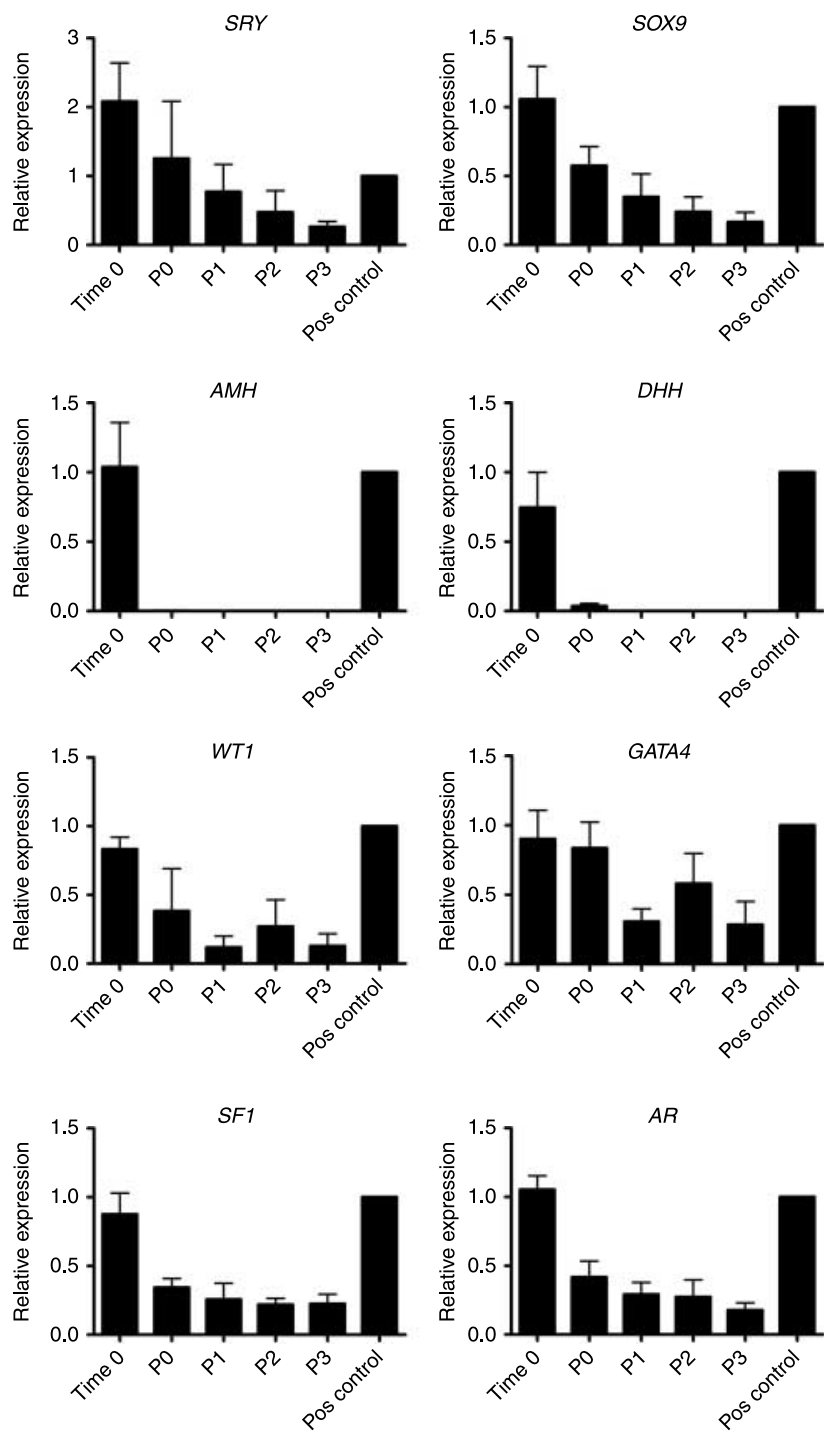

Figure 4 Expression of mRNAs encoding proteins expressed in Sertoli cells in somatic cell monolayers cultured in the presence of DHT. Expression of SOX9, SRY, AMH, DHH, WT1, GATA4, and SF1 mRNAs is shown relative to tissue recovered at the time of dissection $(t=0)$ and the positive control (RNA from pooled fetal testes). Analysis was performed on four separate cultures (originally established from testes at 14-17 weeks of gestation). Mean \pm S.E.M.

in the presence of dihydrotestosterone (DHT) was similar to that in cultures maintained in the absence of androgen, with the former detectable up to and including P3 and the latter undetectable in dissociated cells (compare Figs 3 and 4). Expression of other SC-specific mRNAs was variable. Expression of desert hedgehog $(D H H)$ mirrored that of $A M H$ but expression of mRNAs encoding the transcription factors SRY, WT1, GATA4, and SF1, all of which have been implicated in SOX9 and $A M H$ expression, was detected in all cultures (although overall expression appeared to decline with increasing passage number). 

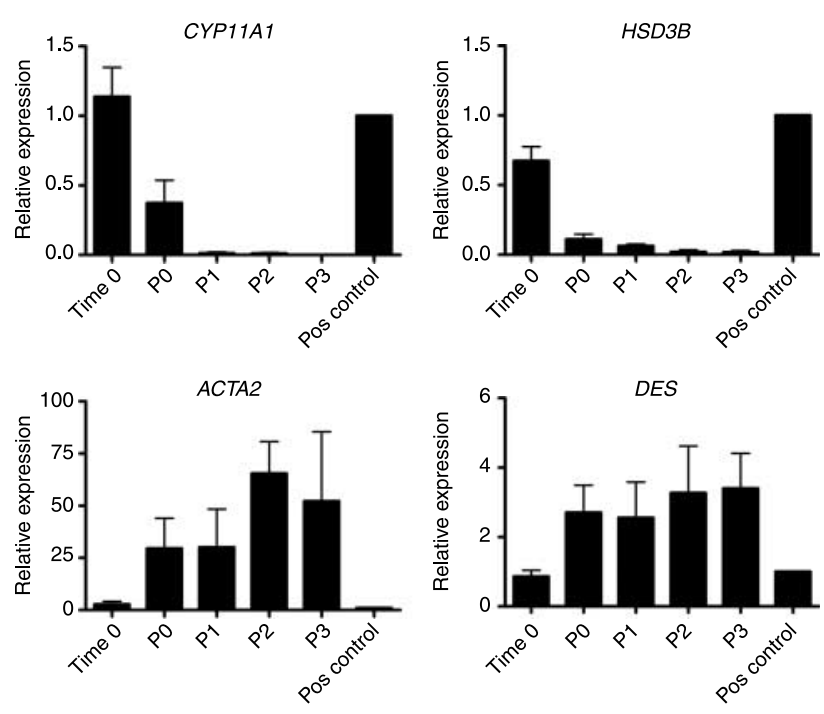

Figure 5 Expression of mRNAs expressed in Leydig cells and PTM/interstitial fibroblasts in somatic cell cultures. The amounts of mRNAs encoding CYP11A1, HSD3B, ACTA2, and DES were determined by qRT-PCR. Analysis was performed on P0 to P3 cultures originally established from four separate fetuses (14-17 weeks of gestation). Expression levels are compared to a samples obtained at the time of tissue recovery $(t=0)$ and a pooled positive control. Mean士s.E.M.

The addition of DHT to cultures also had no impact on total expression of LC-specific mRNAs such as CYP11A1 and $H S D 3 B$ compared with untreated cultures (Fig. 5). Levels of $C Y P 11 A 1$ and $H S D 3 B$ mRNA were significantly reduced when compared with $t=0$ (for CYP11A1 at P0, $P<0.05$ and at P1, P2, and P3, $P<0.01$; for $H S D 3 B$ at P0 and $\mathrm{P} 1, P<0.05$ and at $\mathrm{P} 2$ and $\mathrm{P} 3, P<0.01)$. In contrast, as the number of cell passages increased, total expression of ACTA2, an mRNA expressed in differentiated PTM, increased significantly with P2 and P3 higher than $t=0$ $(P<0.01$ and $P<0.05$ respectively). Total expression of $A R$ mRNA at P0, P1, P2, and P3 was significantly lower than at $t=0 \quad(P<0.05)$, although mRNA was still detectable at P3 (Fig. 4). The levels of transcripts encoding DES appeared higher in cultures than in extracts from intact testes; however, this was not significant and did not vary with passage number (Fig. 5).

\section{Discussion}

In this study, single-cell suspension prepared by collagenase digestion of second trimester human fetal testes was used to establish viable monolayers with mixed cellular morphologies capable of multiple rounds of cell division in vitro. While establishment of shortterm cultures has been described previously, we believe this is the first paper to document the impact of long-term culture on somatic cells obtained from the human fetal testis. Previous studies described monolayer cultures of human fetal testicular cells maintained for up to 6 days (Berensztein et al. 2000) or 20 days (Ahmed et al. 2009).
In the second paper, the authors demonstrated cell proliferation based on incorporation of BrdU and noted that expression of the SC protein clusterin was reduced after 20 days. Cells were not passaged, and therefore, the only direct comparison we could make to our own cultures would be those described here as P0. An alternative method for studying the impact of factors on fetal testicular tissues has been provided by organ cultures (Bendsen et al. 2001, Robinson et al. 2003, Lambrot et al. 2006b, 2009, Hallmark et al. 2007). Expression of $\mathrm{AMH}$ and germ cell mitosis has been reported (Bendsen et al. 2001, Lambrot et al. 2009).

Immunohistochemical staining was used to verify the expression of specific cell markers for the SC, LC, and PTM cell lineages in human fetal testis from the same gestational ages as those used for cell isolation. SC-specific immunoexpression of SOX9 and AMH was in agreement with other studies (De Santa Barbara et al. 1998, Hanley et al. 2000, Gaskell et al. 2004), and as expected, there was a prominent population of LC immunopositive for the steroidogenic enzymes HSD3B and CYP11A1 within the interstitium (Murray et al. 2000, Gaskell et al. 2004, Ostrer et al. 2007). Immunopositive staining for AR, ACTA2, and DES was detected exclusively in interstitial cell populations including a population of PTM cells that were immunopositive for all three proteins. Expression of ACTA2 and AR has been previously reported in PTM and vascular cells of the human fetal testis (Gaskell et al. 2004, Ostrer et al. 2007). However, we believe that the current study is the first to report expression of DES in the human fetal testis, and to demonstrate that in common with $A R$, it is expressed in a wider population of interstitial cells than ACTA2.

Although cells with a variety of morphologies were identifiable in the monolayers, germ cell-specific mRNAs (e.g. POU5F1, DDX4; Anderson et al. 2007) were not detected, suggesting that all the cells growing in the monolayers were somatic in origin. This is consistent with similar methodologies being used to separate oocytes from ovarian somatic cells by adhesion of the latter in culture (Eppig et al. 2000). The identity of the somatic cell populations in the monolayer cultures was further investigated using immunohistochemistry and quantitative RT-PCR. The SC-specific mRNAs encoded by the SRY and SOX9 genes were both expressed in all cultures up to and including P3 but expression of $A M H$ and $D H H$, the products of which are secreted by fetal SC in vivo, was not detected in cultures established from dissociated cells. Studies in mice have identified a number of transcription factors capable of binding to the Amh promoter including SOX9 (Arango et al. 1999). In the undifferentiated mouse gonad, cytoplasmic expression of SOX9 is present in both sexes, but in males the protein translocates to the nucleus following sexual differentiation, with upregulation of Amh occurring thereafter (Morais da Silva et al. 1996), a pattern that is conserved in the developing human 
testis (De Santa Barbara et al. 1998). The Amh promoter also contains numerous GATA4- and SF1-binding sites (Watanabe et al. 2000), and it has been reported that WT1 and GATA4 act synergistically to regulate the transcriptional output from the Amh promoter (Miyamoto et al. 2008). As expression of AMH was not maintained in our cell monolayers despite the presence of a population of cells with SOX9-positive nuclei, we also investigated whether other transcription factors were expressed. These investigations revealed that in addition to SOX9, mRNAs encoding WT1, GATA4 and SF1 were all present. The absence of $\mathrm{AMH}$ expression in our cultures may therefore arise from a decline in levels of the aforementioned proteins below the threshold required to drive transcription from the $\mathrm{AMH}$, loss of stimulation due to the absence of factors produced by other cell types within the fetal testis, or loss of expression of an as-yet unidentified transcription factor required for $A M H$ expression. Notably, although the monolayer cultures contained cells identified as differentiated LC, expression of steroidogenic enzymes was not detected after P2, suggesting that either the cells failed to survive and proliferate within the cultures, or that they lost their steroidogenic capacity. As SCs play a pivotal role in determining LC fate, partial dedifferentiation of SC (i.e. the failure to express AMH and $\mathrm{DHH}$; Clark et al. 2000, Yao et al. 2002) may contribute to the loss/dedifferentiation of the LCs.

The expression of ACTA2 and DES mRNAs was maintained or increased as a proportion of total mRNA at higher passage numbers (P2 and above), and this was consistent with an increase in the proportion of ACTA2immunopositive cells in the monolayers. Immunostaining of intact testis revealed that ACTA2 was restricted to the PTM cells and myoepithelial cells of the blood vessels but was not found in the interstitial fibroblasts. A previous study reported that fibroblasts from a number of tissues convert to a myofibroblast phenotype as a consequence of their in vitro environment (Dugina et al. 1998). Expression of $A R$ mRNA was detectable in all cultures regardless of passage number; as immunohistochemical evaluation of second trimester testes (current study; Gaskell et al. 2004) has demonstrated that AR is only detectable in interstitial cells at this stage of gestation, we anticipate that this cell population is also responsible for expression of $A R$ mRNA in our cultures. In cultures grown in the presence of DHT, a significant increase in expression of ACTA2 mRNA was observed with increasing passage number a result that appears consistent with reports that exposure to androgens can promote commitment of cells to a myogenic lineage (Singh et al. 2003). With increasing passage number, the time to confluency decreased and the numbers of long flat cells increased suggesting that more rapidly dividing cells were overtaking the cultures. Detection of DES mRNA up to and including P3 suggests survival of interstitial fibroblasts as well as PTM cells and would be consistent with reports that fibroblasts can survive and overtake other cell types when cultured in the presence of serum (Singer et al. 1989). Although in vivo the fetal testis develops in the presence of high concentrations of androgens synthesised by the fetal LC, incubation of mixed cell monolayers with DHT appeared to have no significant impact on mRNAs expressed in SC or LC. Studies in mice using cell-specific ablation of $A r$ in SC (De Gendt et al. 2005) or PTM (Welsh et al. 2009) suggest that androgen-dependent changes in cell function of the different populations of the different somatic cells present within the testis can have an impact on the function of adjacent cell populations within the adult testis. However, these studies have not revealed any cell-specific role for AR in the fetal rodent testis. Notably, AR is not expressed until after birth in mouse SC and Welsh et al. (2009) only observed a testicular phenotype on and after post natal day 15, even though Ar was deleted from fetal PTM at e17.5. Our results suggest that androgens maintain/promote differentiation of the PTM cell population in our cultures; however, we found no evidence of crosstalk with the SC population. Although it was previously proposed that fetal PTM cells arise from a population of cells migrating into the testis from the mesonephros (Buehr et al. 1993), this is now disputed (Cool et al. 2008) and further studies are therefore required to determine the impact of androgens on gene expression in fetal PTM cells.

In conclusion, a method for long-term in vitro culture of human fetal somatic cells has been established. We found that long-term culture of these cells results in the downregulation in expression of mRNAs specific for Sertoli and LCs, suggesting that these cells either did not thrive or that alterations occurred to their phenotype. Repeated passage of cells in the presence of DHT favored the differentiation of cells expressing ACTA2 and therefore provides us with a model system in which to study regulation of gene expression in cells with a phenotype consistent with that of the fetal PTM cells, a population whose function remains unexplored.

\section{Materials and Methods}

\section{Tissue collection}

Human fetal testes were obtained following elective termination of pregnancy as dated from last menstrual period during the second trimester (14-19 weeks gestation). Women gave written consent according to the national guidelines (Polkinghorne 1989) with the protocol approved by the Lothian Research Ethics Committee. Termination of pregnancy was induced by treatment with mifepristone (200 mg, orally), followed by misoprostol (Pharmacia; $200 \mathrm{mg}$ every $3 \mathrm{~h}$, per vaginam). None of the terminations were for reasons of fetal abnormality, with all fetuses appearing morphologically normal. Gestational age was determined prior to termination by ultrasound examination and subsequently confirmed by direct measurement of foot length. Testes were carefully 
Table 1 Summary of primary antibodies used for immunohistochemistry.

\begin{tabular}{|c|c|c|c|c|}
\hline Antigen & Source & Species & Dilution & $\begin{array}{l}\text { Citrate } \\
\text { retrieval }\end{array}$ \\
\hline HSD3B & $\begin{array}{l}\text { Gift from Prof. Ian } \\
\text { Mason, University } \\
\text { of Edinburgh }\end{array}$ & Rabbit & $1: 1000$ & No \\
\hline $\mathrm{AMH}$ & Santa Cruz & Goat & $1: 500$ & No \\
\hline DES & Dako & Mouse & $1: 200$ & Yes \\
\hline CYP11A1 & Chemicon & Rabbit & $1: 200$ & No \\
\hline SOX9 & Chemicon & Rabbit & $1: 200$ & Yes \\
\hline ACTA2 & Sigma & Mouse & $1: 200$ & No \\
\hline
\end{tabular}

dissected from the abdominal cavity of the fetus, associated ducts removed, and processed immediately. For tissue to be used in cultures, a small piece was removed and snap frozen and stored at $-70{ }^{\circ} \mathrm{C}$ (reference sample $t=0$ ), and the remaining tissue was dissociated (see below). Some testes were fixed in Bouins fluid for 2-3 h, stored in $70 \%$ ethanol, and processed into paraffin wax using standard methods.

\section{Immunohistochemistry}

Immunohistochemistry was performed using standard methods (Mitchell et al. 2008). Sections $(5 \mu \mathrm{m})$ were mounted on charged glass slides (BDH Chemicals, Poole, UK), dewaxed, rehydrated, and subjected to heat-induced antigen retrieval in $0.1 \mathrm{M}$ citrate $(\mathrm{pH} \mathrm{6)}$ as required (see Table 1). Endogenous peroxidase activity was blocked as previously described (Mitchell et al. 2008); primary antibodies diluted in normal serum $/ 5 \%$ BSA/TBS (Table 1) were incubated on sections overnight at $4{ }^{\circ} \mathrm{C}$. Thereafter, sections were washed in TBS and incubated for $30 \mathrm{~min}$ with the appropriate biotinylated secondary antibody (Dako, Cambridgeshire, UK) diluted 1:500 in BSA/TBS. Following washes in TBS, sections were incubated with avidin-biotin-HRP complex (Vector Laboratories UK, Peterborough, UK), and specific staining was visualised using 3,3-diaminobenzidine tetrahydrochloride (Dako). Negative controls, incubated with blocking serum alone, were included in each experiment.

\section{Dissociation and culture of cells from human fetal testes}

Immediately after recovery, testicular tissue was placed in $4 \mathrm{ml}$ of Hank's buffered salt solution (HBSS) and carefully pulled apart using sterile 40-mm needles. Further dissociation of tissue was achieved by the addition of $500 \mu$ l of collagenase type IV solution (prepared by dissolving $0.01 \mathrm{~g}$ in $1 \mathrm{ml} \mathrm{HBSS}$ ) followed by incubation for $15 \mathrm{~min}$ at $37^{\circ} \mathrm{C}$ on a roller platform. After addition of $50 \mu \mathrm{l}$ of DNase $1(0.007 \mathrm{~g}$ in $1 \mathrm{ml} \mathrm{HBSS})$, the samples were incubated for a further $5 \mathrm{~min}$. The resulting cell suspension was washed several times using HBSS and gentle centrifugation. Any remaining tissue fragments were removed by filtering the samples through a $70-\mu \mathrm{m}$ mesh filter. Typically, this resulted in a cell suspension of $5-10 \times 10^{6}$ cells depending upon the size (age) of the original testis. In order to encourage cell adhesion, $25 \mathrm{~cm}^{2}$ flasks were coated with $0.01 \%$ gelatin prior to use. The entire population of dissociated cells was suspended in DMEM, 10\% heat-inactivated fetal bovine serum (Invitrogen), 1\% penicillin-streptomycin, 1\% nonessential amino acids, $1 \%$ fungizone, $1 \%$ of $2 \mathrm{mM}$ L-glutamine, $1 \%$ $\mathrm{D}(+)$-glucose and introduced into a single flask. Media was changed after 2 days to remove nonadherent cells. Cultures were passaged when adherent cells became confluent, which normally occurred within a week; nonadherent cells were discarded, and cell monolayers were dissociated using trypsin/EDTA. All reagents were from Sigma unless otherwise specified. In the current paper, data are presented from cultures up to and including P3; however, exploratory studies in the laboratory indicated that cells were viable and proliferating up to and including P8 at which time they were terminated. Preliminary investigations suggested that cells were capable of surviving freezing and would re-establish monolayers; thereafter, however, detailed characterisation was not undertaken due to lack of time.

\section{RNA extraction and quantitative RT-PCR}

Total RNA was extracted from fetal gonads and somatic cell cultures using the RNeasy Mini Kit (Qiagen) with on-column DNase digestion (Qiagen), RNA concentrations were measured and were typically in the range $200-300 \mathrm{ng} / \mu \mathrm{l}$ in $50 \mu \mathrm{l}$. cDNA was prepared using reverse transcriptase and random hexamers (Applied Biosystems RT Kit, Applied Biosystems, Warrington, UK), and real-time quantitative (q)PCR was performed using the $\mathrm{ABI}$ prism sequence detection system (Applied Biosystems) and primers from the Roche Universal Probe Library (Roche Applied Science). Details of primer sequences and the identifier numbers of the probe samples are listed in Table 2. The expression levels of each of the genes of interest were calculated using an endogenous control 18S rRNA (Applied Biosystems Cat \#4308329), and all data were expressed relative to a positive control (pooled RNA from three whole human fetal testes), which was included in all experiments. Each Taqman reaction was performed in triplicate on a Microamp Fast Optical 96-well reaction plate (Applied Biosystems). Statistical analysis was performed using a one-way ANOVA followed by a Bonferroni's multiple comparison test.

Table 2 Summary of primers and probes used for Taqman reactions.

\begin{tabular}{|c|c|c|c|}
\hline $\begin{array}{l}\text { Gene } \\
\text { name }\end{array}$ & $5^{\prime}$ Sequence & $3^{\prime}$ Sequence & $\begin{array}{l}\text { Probe } \\
\text { number }\end{array}$ \\
\hline$H S D 3 B$ & cggaccagaattgagagagg & gaatggctcatccagaatgtc & 11 \\
\hline$A M H$ & cgcctggtggtcctacac & gaacctcagcgagggtgtt & 69 \\
\hline$A R$ & gccttgctctctagcctcaa & gtcgtccacgtgtaagttgc & 14 \\
\hline$D E S$ & ggagattgccacctaccg & ggtctggatggggagattg & 55 \\
\hline $\mathrm{DHH}$ & gcaacaagtatgggttgctg & cggaccgcagtgagtta & 86 \\
\hline GATA4 & ggaagcccaagaacctgaat & gggaggaaggctctcactg & 17 \\
\hline CYP11A1 & aggaggggtggacacgac & ttgcgtgccatctcataca & 59 \\
\hline SF1 & gcaggtgcatggtcttcaa & agttctgcagcagcgtcat & 10 \\
\hline ACTA2 & ctgttccagccatccttcat & gatgctgttgtaggtggtttca & 58 \\
\hline SOX9 & gtacccgcacttgcacaас & tctcgctctcgttcagaagtc & 61 \\
\hline$S R Y$ & gcttactgaagccgaaaaaatg & tctctgtgcatggcctgtaa & 79 \\
\hline WT1 & agctgtcccacttacagatgc & ccttgaagtcacactggtatgg & 4 \\
\hline
\end{tabular}

${ }^{a}$ Roche Universal Probelibrary set, Human (Cat. No. 04683633001). 


\section{Immunolocalisation of proteins in cell monolayers}

Cells were grown on poly L-lysine-coated CC2 chamber slides (Lab-Tek, Nalge Nunc International, Roskilde, Denmark) until confluent then fixed in Modified Davidson's Fixative $(30 \%$ formaldehyde (37\%), 15\% ethanol, 5\% glacial acetic acid, and $50 \% \mathrm{H}_{2} \mathrm{O}$ ) for $10 \mathrm{~min}$ at room temperature, followed by $2 \times 5$ min washes in PBS. Nonspecific binding was blocked by incubating cells in PBS containing 20\% normal serum and $5 \%$ BSA, followed by reagents from the avidin-biotin blocking kit (Anderson et al. 2007). Primary antibodies (anti-SOX9, 1:300; anti-ACTA2, 1:200; anti-CYP11A1 1:100) were diluted as above and incubated on cells overnight at $4{ }^{\circ} \mathrm{C}$. After $2 \times 5$ min washes in PBS, cells were incubated with the appropriate secondary antibody, diluted in normal serum, then rewashed in PBS $(2 \times 5 \mathrm{~min})$ and incubated with Streptavidin 546 (Molecular Probes, Leiden, The Netherlands) (1:200 in PBS) for $1 \mathrm{~h}$. Cells were rewashed in PBS, counterstained with DAPI (Sigma), mounted in permaflour (Immunotech, Marseille, France), and image capture was performed on a Meta confocal microscope (Carl Zeiss, Hertfordshire, UK).

\section{Declaration of interest}

The authors declare that there is no conflict of interest that could be perceived as prejudicing the impartiality of the research reported.

\section{Funding}

This work was supported by MRC HRSU Unit core funding to $\mathrm{P}$ T K Saunders (U.1276.00.002.00005.01) and R A Anderson (U.1276.00.002.00001.01).

\section{Acknowledgements}

We are grateful to Joan Creiger, Anne Saunderson, and the staff of the Bruntsfield suite, Royal Infirmary of Edinburgh for work in support of this study.

\section{References}

Ahmed EA, Barten-van Rijbroek AD, Kal HB, Sadri-Ardekani H, Mizrak SC, van Pelt AM \& de Rooij DG 2009 Proliferative activity in vitro and DNA repair indicate that adult mouse and human Sertoli cells are not terminally differentiated, quiescent cells. Biology of Reproduction 80 1084-1096.

Anderson RA, Fulton N, Cowan G, Coutts S \& Saunders PT 2007 Conserved and divergent patterns of expression of DAZL, VASA and OCT4 in the germ cells of the human fetal ovary and testis. BMC Developmental Biology 7136.

Arango NA, Lovell-Badge R \& Behringer RR 1999 Targeted mutagenesis of the endogenous mouse Mis gene promoter: in vivo definition of genetic pathways of vertebrate sexual development. Cell 99 409-419.

Askew EB, Gampe RT Jr, Stanley TB, Faggart JL \& Wilson EM 2007 Modulation of androgen receptor activation function 2 by testosterone and dihydrotestosterone. Journal of Biological Chemistry 282 25801-25816.

Bendsen E, Laursen S, Olesen C, Westergaard L, Andersen C \& Byskov A 2001 Effect of 4-octylphenol on germ cell number in cultured human fetal gonads. Human Reproduction 16 236-243.
Berensztein EB, Belgorosky A \& Rivarola MA 1992 Primary culture of prepubertal human testicular cells isolated from testes collected at necropsy. Acta Endocrinologica 127 66-71.

Berensztein E, Saraco N, Belgorosky A \& Rivarola MA 2000 Secretion of inhibin B by human prepubertal testicular cells in culture. European Journal of Endocrinology 142 481-485.

Bishop CE, Whitworth DJ, Qin Y, Agoulnik AI, Agoulnik IU, Harrison WR, Behringer RR \& Overbeek PA 2000 A transgenic insertion upstream of sox 9 is associated with dominant $\mathrm{XX}$ sex reversal in the mouse. Nature Genetics 26 490-494.

Brennan J \& Capel B 2004 One tissue, two fates: molecular genetic events that underlie testis versus ovary development. Nature Reviews. Genetics 5 509-521.

Buehr M, Gu S \& McLaren A 1993 Mesonephric contribution to testis differentiation in the fetal mouse. Development 117 273-281.

Bullejos M \& Koopman P 2001 Spatially dynamic expression of Sry in mouse genital ridges. Developmental Dynamics 221 201-205.

Clark AM, Garland KK \& Russell LD 2000 Desert hedgehog (Dhh) gene is required in the mouse testis for formation of adult-type Leydig cells and normal development of peritubular cells and seminiferous tubules. Biology of Reproduction 63 1825-1838.

Combes AN, Wilhelm D, Davidson T, Dejana E, Harley V, Sinclair A \& Koopman P 2009 Endothelial cell migration directs testis cord formation. Developmental Biology 326 112-120.

Cool J, Carmona FD, Szucsik JC \& Capel B 2008 Peritubular myoid cells are not the migrating population required for testis cord formation in the $\mathrm{XY}$ gonad. Sexual Development 2 128-133.

Coutts SM, Fulton N \& Anderson RA 2007 Environmental toxicant-induced germ cell apoptosis in the human fetal testis. Human Reproduction 22 2912-2918.

De Gendt K, Atanassova N, Tan KA, de Franca LR, Parreira GG, McKinnell C, Sharpe RM, Saunders PT, Mason JI, Hartung S et al. 2005 Development and function of the adult generation of Leydig cells in mice with Sertoli cell-selective or total ablation of the androgen receptor. Endocrinology 146 4117-4126.

De Santa Barbara P, Bonneaud N, Boizet B, Desclozeaux M, Moniot B, Sudbeck P, Scherer G, Poulat F \& Berta P 1998 Direct interaction of SRY-related protein SOX9 and steroidogenic factor 1 regulates transcription of the human anti-Mullerian hormone gene. Molecular and Cellular Biology 18 6653-6665.

Dugina V, Alexandrova A, Chaponnier C, Vasiliev J \& Gabbiani G 1998 Rat fibroblasts cultured from various organs exhibit differences in alphasmooth muscle actin expression, cytoskeletal pattern, and adhesive structure organization. Experimental Cell Research 238 481-490.

Eppig JJ, Wigglesworth K \& Hirao Y 2000 Metaphase I arrest and spontaneous parthenogenetic activation of strain LTXBO oocytes: chimeric reaggregated ovaries establish primary lesion in oocytes. Developmental Biology 224 60-68.

Gao F, Maiti S, Alam N, Zhang Z, Deng JM, Behringer RR, Lecureuil C, Guillou F \& Huff V 2006 The Wilms tumor gene, Wt1, is required for Sox9 expression and maintenance of tubular architecture in the developing testis. PNAS 103 11987-11992.

Gaskell TL, Esnal A, Robinson LL, Anderson RA \& Saunders PT 2004 Immunohistochemical profiling of germ cells within the human fetal testis: identification of three subpopulations. Biology of Reproduction 71 2012-2021.

Hacker A, Capel B, Goodfellow P \& Lovell-Badge R 1995 Expression of Sry, the mouse sex determining gene. Development 121 1603-1614.

Hallmark N, Walker M, McKinnell C, Mahood IK, Scott H, Bayne R, Coutts S, Anderson RA, Greig I, Morris K et al. 2007 Effects of monobutyl and di(n-butyl) phthalate in vitro on steroidogenesis and Leydig cell aggregation in fetal testis explants from the rat: comparison with effects in vivo in the fetal rat and neonatal marmoset and in vitro in the human. Environmental Health Perspectives 115 390-396.

Hanley NA, Hagan DM, Clement-Jones M, Ball SG, Strachan T, Salas-Cortes L, McElreavey K, Lindsay S, Robson S, Bullen P et al. 2000 SRY, SOX9, and DAX1 expression patterns during human sex determination and gonadal development. Mechanisms of Development 91 403-407.

Lambrot R, Coffigny H, Pairault C, Donnadieu AC, Frydman R, Habert R \& Rouiller-Fabre V 2006a Use of organ culture to study the human fetal testis development: effect of retinoic acid. Journal of Clinical Endocrinology and Metabolism 91 2696-2703. 
Lambrot R, Livera G, Coffigny H, Pairault C, Frydman R, Habert R \& Rouiller-Fabre V 2006b A new method for toxicity assays on human and mouse fetal testis. Biochimie 88 1831-1835.

Lambrot R, Muczynski V, Lecureuil C, Angenard G, Coffigny H, Pairault C, Moison D, Frydman R, Habert R \& Rouiller-Fabre V 2009 Phthalates impair germ cell development in the human fetal testis in vitro without change in testosterone production. Environmental Health Perspectives 117 32-37.

Majdic G, Millar MR \& Saunders PT 1995 Immunolocalisation of androgen receptor to interstitial cells in fetal rat testes and to mesenchymal and epithelial cells of associated ducts. Journal of Endocrinology 147 285-293.

Manuylov NL, Fujiwara Y, Adameyko II, Poulat F \& Tevosian SG 2007 The regulation of Sox9 gene expression by the GATA4/FOG2 transcriptional complex in dominant XX sex reversal mouse models. Developmental Biology 307 356-367.

Mitchell RT, Cowan G, Morris KD, Anderson RA, Fraser HM, McKenzie KJ, Wallace WH, Kelnar CJ, Saunders PT \& Sharpe RM 2008 Germ cell differentiation in the marmoset (Callithrix jacchus) during fetal and neonatal life closely parallels that in the human. Human Reproduction 23 2755-2765.

Miyamoto Y, Taniguchi H, Hamel F, Silversides DW \& Viger RS 2008 A GATA4/WT1 cooperation regulates transcription of genes required for mammalian sex determination and differentiation. BMC Molecular Biology 944.

Morais da Silva S, Hacker A, Harley V, Goodfellow P, Swain A \& Lovell-Badge R 1996 Sox9 expression during gonadal development implies a conserved role for the gene in testis differentiation in mammals and birds. Nature Genetics 14 62-68.

Murray TJ, Fowler PA, Abramovich DR, Haites N \& Lea RG 2000 Human fetal testis: second trimester proliferative and steroidogenic capacities. Journal of Clinical Endocrinology and Metabolism 85 4812-4817.

Nishino K, Yamanouchi K, Naito K \& Tojo H 2001 Characterization of mesonephric cells that migrate into the $X Y$ gonad during testis differentiation. Experimental Cell Research 267 225-232.

Ostrer H, Huang HY, Masch RJ \& Shapiro E 2007 A cellular study of human testis development. Sexual Development $1286-292$.

Polkinghorne J 1989 Review of the Guidance on the Research Use of Fetuses and Fetal Material, London: HMSO.

Rajpert-De Meyts E, Jorgensen N, Graem N, Muller J, Cate RL \& Skakkebaek NE 1999 Expression of anti-Mullerian hormone during normal and pathological gonadal development: association with differentiation of Sertoli and granulosa cells. Journal of Clinical Endocrinology and Metabolism 84 3836-3844.
Rivarola MA, Belgorosky A, Berensztein E \& de Davila MT 1995 Human prepubertal testicular cells in culture: steroidogenic capacity, paracrine and hormone control. Journal of Steroid Biochemistry and Molecular Biology 53 119-125.

Robinson LL, Townsend J \& Anderson RA 2003 The human fetal testis is a site of expression of neurotrophins and their receptors: regulation of the germ cell and peritubular cell population. Journal of Clinical Endocrinology and Metabolism 88 3943-3951.

Sekido R \& Lovell-Badge R 2008 Sex determination involves synergistic action of SRY and SF1 on a specific Sox9 enhancer. Nature 453 930-934.

Singer KH, Scearce RM, Tuck DT, Whichard LP, Denning SM \& Haynes BF 1989 Removal of fibroblasts from human epithelial cell cultures with use of a complement fixing monoclonal antibody reactive with human fibroblasts and monocytes/macrophages. Journal of Investigative Dermatology 92 166-170.

Singh R, Artaza JN, Taylor WE, Gonzalez-Cadavid NF \& Bhasin S 2003 Androgens stimulate myogenic differentiation and inhibit adipogenesis in $\mathrm{C} 3 \mathrm{H} 10 \mathrm{~T} 1 / 2$ pluripotent cells through an androgen receptor-mediated pathway. Endocrinology 144 5081-5088.

Sneddon SF, Walther N \& Saunders PT 2005 Expression of androgen and estrogen receptors in Sertoli cells: studies using the mouse SK11 cell line. Endocrinology 146 5304-5312.

Vidal VP, Chaboissier MC, de Rooij DG \& Schedl A 2001 Sox9 induces testis development in XX transgenic mice. Nature Genetics 28 216-217.

Walther N, Jansen M, Ergun S, Kascheike B \& Ivell R 1996 Sertoli cell lines established from $\mathrm{H}-2 \mathrm{~Kb}$-tsA58 transgenic mice differentially regulate the expression of cell-specific genes. Experimental Cell Research 225 411-421.

Watanabe K, Clarke TR, Lane AH, Wang X \& Donahoe PK 2000 Endogenous expression of Mullerian inhibiting substance in early postnatal rat Sertoli cells requires multiple steroidogenic factor- 1 and GATA-4-binding sites. PNAS 97 1624-1629.

Welsh M, Saunders PT, Atanassova N, Sharpe RM \& Smith LB 2009 Androgen action via testicular peritubular myoid cells is essential for male fertility. FASEB Journal 23 4218-4230.

Yao HH, Whoriskey W \& Capel B 2002 Desert Hedgehog/Patched 1 signaling specifies fetal Leydig cell fate in testis organogenesis. Genes and Development 16 1433-1440.

Received 27 November 2009

First decision 5 January 2010

Accepted 20 January 2010 